“Official ERS technical standards: Global Lung Function Initiative reference values for the carbon monoxide transfer factor for Caucasians." Sanja Stanojevic, Brian L. Graham, Brendan G. Cooper, Bruce R. Thompson, Kim W. Carter, Richard W. Francis and Graham L. Hall on behalf of the Global Lung Function Initiative $T_{\text {Lco }}$ working group. Eur Respir J 2017; 50: 1700010.

\title{
From the authors:
}

It was recently brought to our attention that females with low $T_{\mathrm{LCO}}$ values had exceptionally low z-scores when calculated using the Global Lung Function Initiative (GLI) $T_{\mathrm{LCO}}$ calculator. We subsequently looked through the models and original data and identified an anomaly, which was likely due to a discrepancy in the label that was assigned to sex in one of the datasets ( $n=282$ females; $n=259$ males). Upon identifying this source of error, we re-analysed the data excluding this centre and recalculated the predicted values and tables (please refer to the table below; this replaces table 2 in the originally published manuscript) The updated equations were derived from 4577 males and 4592 females between 5 and 80 years of age.

The primary difference is in the predicted values for adult females, and for the calculation of z-scores in adult females (figure 1); there will be minimal differences in the percent predicted values (average percent predicted change $1.02 \%$, with a standard deviation of $2.0 \%$ ). Although the differences in males were minimal (average percent predicted change $0.6 \%$, standard deviation $0.4 \%$ ), the prediction equations for males also changed in the re-analysis. The error did not impact the overall conclusions regarding corrections for altitude, dead space or the minimal differences observed between equipment and centre.

Although every effort was made to harmonise and clean the data, regrettably this was an error that was missed by our team. We recognise that this will impact on previously calculated values and will make every effort to notify the respiratory community, including the manufacturers, to ensure the updated formulas are implemented. The online GLI calculators at www.lungfunction.org have been corrected. Table 2 in the published manuscript has been corrected according to the updated equations, and the relevant supplementary files have been replaced. 
TABLE 2 The corrected equations for predicted values for the median (M), the variability around the median (S) and the skewness (L) for each of the $T_{\text {LCo }}$ test outcomes (transfer factor of the lung for carbon monoxide ( $\left.T_{L C O}\right)$, transfer coefficient of the lung for carbon monoxide $\left(K_{\mathrm{CO}}\right)$ and alveolar volume $\left(V_{\mathrm{A}}\right)$ )

M S S L

\section{Male}

$T_{\mathrm{Lco}} \mathrm{mmol} \cdot \mathrm{min}^{-1} \cdot \mathrm{kPa}^{-1}$

$D_{\mathrm{LCO}} \mathrm{mL} \cdot \mathrm{min}^{-1} \cdot \mathrm{mmHg}^{-1}$

$\exp (-8.129189+2.018368 \cdot \ln ($ height $)-0.012425 \cdot \ln ($ age $)+$ Mspline $)$ $\exp (-7.034920+2.018368 \cdot \ln ($ height) $-0.012425 \cdot \ln ($ age $)+$ Mspline

$K_{\mathrm{CO}}$ (SI) $\mathrm{mmol} \cdot \mathrm{min}^{-1} \cdot \mathrm{kPa}^{-1} \cdot \mathrm{L}^{-1}$

$K_{\text {CO }}$ (trad) $\mathrm{mL} \cdot \mathrm{min}^{-1} \cdot \mathrm{mmHg}^{-1} \cdot \mathrm{L}^{-1}$

$\exp (2.994137-0.415334 \cdot \ln ($ height $)-0.113166 \cdot \ln ($ age $)+$ Mspline) $\exp (4.088408-0.415334 \cdot \ln ($ height) $-0.113166 \cdot \ln ($ age $)+$ Mspline $)$

$\exp (-1.98996+0.03536 \cdot \ln ($ age $)+$ Sspline $)$

0.39482

$\exp (-1.98186+0.01460 \cdot \ln ($ age $)+$ Sspline $)$

0.67330

$\exp (-11.086573+2.430021 \cdot \ln ($ height $)+0.097047 \cdot \ln ($ age $)+$ Mspline $)$

$\exp (-2.20953+0.01937 \cdot \ln ($ age $)+$ Sspline $)$

0.62559

\section{Female}

$T_{\text {LCO }} \mathrm{mmol} \cdot \mathrm{min}^{-1} \cdot \mathrm{kPa}^{-1}$

$D_{\text {LCO }} \mathrm{mL} \cdot \mathrm{min}^{-1} \cdot \mathrm{mmHg}^{-1}$

$K_{\mathrm{CO}}$ (SI) $\mathrm{mmol} \cdot \mathrm{min}^{-1} \cdot \mathrm{kPa}^{-1} \cdot \mathrm{L}^{-1}$

$K_{\mathrm{CO}}$ (trad) $\mathrm{mL} \cdot \mathrm{min}^{-1} \cdot \mathrm{mmHg}^{-1} \cdot \mathrm{L}^{-1}$

$\exp (-6.253720+1.618697 \cdot \ln ($ height $)-0.015390 \cdot \ln ($ age $)+$ Mspline $\exp (-5.159451+1.618697 \cdot \ln ($ height $)-0.015390 \cdot \ln ($ age $)+$ Mspline

$\exp (4.037222-0.645656 \cdot \ln ($ height $)-0.097395 \cdot \ln ($ age $)+$ Mspline) $\exp (5.131492-0.645656 \cdot \ln ($ height $)-0.097395 \cdot \ln ($ age $)+$ Mspline)

$\exp (-9.873970+2.182316 \cdot \ln ($ height $)+0.082868 \cdot \ln ($ age $)+$ Mspline $)$

$V_{\mathrm{A}} \mathrm{L}$

Mspline, Sspline correspond to the age-varying coefficients from the look-up tables provided in the supplementary material. Height and age are expressed as $\mathrm{cm}$ and years, respectively.

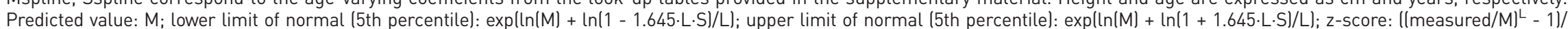
(L.S); \% predicted: (measured/M).100; exp: natural exponential; In: natural logarithm. This table has been amended in the article originally published in the September 2017 issue of the European Respiratory Journal. 

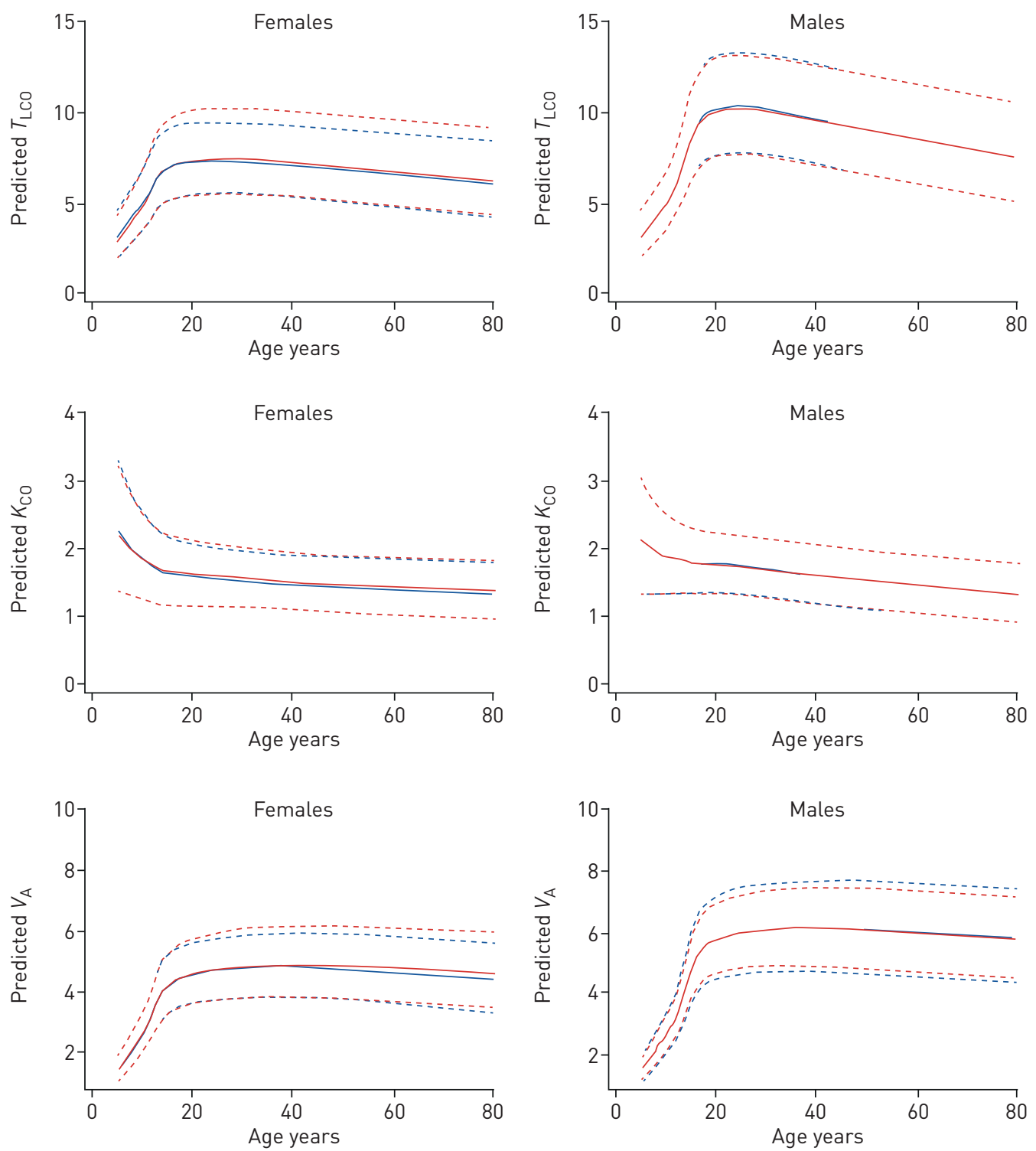

FIGURE 1 Summary of differences in the predicted values using the original Global Lung Function Initiative (GLI) equations (red) and the updated equations (blue).

Copyright @ERS 2020 